\title{
Ortaokul Öğrencilerinin Matematiğe İlişkin İnançları
}

\section{Middle School Students' Beliefs About Mathematics}

\author{
Pinar YILDIZ ${ }^{1}$
}

Yayına Kabul Tarihi: 10.08.2016

DOI: $10.21764 /$ efd.91453

\begin{abstract}
Başvuru Tarihi: 01.04.2016
Özet: $\mathrm{Bu}$ araştırma ortaokul öğrencilerinin matematiğe ilişkin inançlarını incelemek amacıyla yürütülmüştür. Araştırma, nitel araştırma modellerinden olgu bilim deseni kullanılarak yapılandırılmıştır. Araştırmaya büyük bir ilde öğrenim görmekte olan toplam 252 ortaokul 6,7 ve 8 . sınıf öğrencisi katılmıştır. Öğrencilerin matematiksel inançlarının farklı boyutlarını açığa çıkarabilmek amacıyla 3 açık uçlu soru yazılı olarak yöneltilmiştir. Öğrencilerin matematiksel inançları kullandıkları metaforlar aracılığıyla belirlenmeye çalışılmıştır. Elde edilen veriler içerik analiz yöntemiyle analiz edilmiştir. Araştırma sonucunda öğrencilerin matematiği bilgi verici ve hesaplama yapmak olarak gördükleri belirlenmiştir. Ayrıca öğrencilerin matematiğin akıl ve zekâ gerektirdiğini, matematikte ezberin önemli olduğunu ve matematikte başarılı olmak için çok çalışmanın gerekli olduğunu düşündükleri tespit edilmiştir.
\end{abstract}

\begin{abstract}
This study was conducted to examine middle school students' beliefs about mathematics. The research has been designed using phenomenology approach, which is one of the qualitative research models. A total of 252 middle school students from $6^{\text {th }}, 7^{\text {th }}$ and $8^{\text {th }}$ grades participated in this study. In order to reveal various dimensions of students' mathematical beliefs, 3 open-ended questions were asked in the written form. Mathematical beliefs of the students were determined via the metaphors that they have used. The collected data were analyzed using content analysis. The results of the study showed that students see mathematics as an informative subject and making calculations. Moreover, it was found that students had the following thoughts such as mathematics requires mind and intelligence, memorization is important in mathematics and working hard is necessary for being successful in mathematics.
\end{abstract}

Keywords: Belief, mathematics, middle school students

Anahtar Kelimeler: İnanç, matematik, ortaokul öğrencileri

\section{Giriş}

Öğrencilerin matematiğe ilişkin inançları matematik eğitiminde önemli bir yere sahiptir (McLeod, 1989; Moscucci, 2007). Öğrencilerin matematiksel eğilimi de matematiğe yönelik inançlarıyla ilişkili olup (Wilkins ve Ma, 2003), bu inançlar öğrencilerin matematiğe ve matematiksel görevlere yaklaşımını büyük ölçüde etkilemektedir (Garofalo, 1989). Ayrıca, öğrencilerin matematiksel inançları sınıf içindeki diğer öğrencilerle ve öğrenme ortamıyla etkileşim sürecine de yön veren önemli bir etkiye sahiptir (Op’t Eynde ve De Corte, 2004).

Öğrencilerin inançları temel alınarak yapılan çok sayıda araştırma bulunmasına rağmen, inanç kavramının araştırmacılar tarafından kabul edilmiş evrensel bir tanımı bulunmamaktadır. Bu durumun nedeni inancın farklı yaklaşımlarda farklı şekillerde tanımlanmasıdır (Eleftherios ve Theodosios, 2007; Goldin, Rösken ve Törner, 2009; Kislenko, Grevholm ve Lepik, 2005; McLeod ve McLeod, 2002; Moscucci, 2007; Vanayan, White, Yuen ve Teper, 1997). Cobb (1986) inancı, gerçekliğin doğası hakkındaki kişisel varsayımlar olarak tanımlamaktadır. Elefthherios ve Theodosis (2007) ise inancı, kişinin öznel olarak yapılandırdığı bilişler, kuramlar ve kavramlar olarak tanımlamaktadırlar. Ayrıca inancın mantıksal ve duygusal bir yapısı olduğunu belirtmektedirler. Goldin'e (2002) göre ise inanç, kişinin doğruluk değeri yüklediği genellikle fikirsel kodlamaları içeren çoklu kodlanmış zihinsel yapılardır. Kimi araştırmacılar ise inancı bilginin (Pehkonen ve

\footnotetext{
${ }^{1}$ Arş. Gör. Dr., Erciyes Üniversitesi, Eğitim Fakültesi, İlköğretim Bölümü, pinar_akdal@hotmail.com
} 
Pietila, 2003; Star ve Hoffman, 2005; Törner, 2001) ve tutumun (Pehkonen ve Törner, 1996; Rokeach, 1968) bir parçası olarak açıklamaktadırlar.

Matematiksel inanç ise kişinin matematiğe ve matematiksel görevlere yaklaşımıdır (Schoenfeld, 1989). Raymond'a (1997) göre ise matematiksel inanç kişinin matematik deneyimleri sonucu şekillenen matematik ile ilgili kişisel yargılarıdır. Raymond (1997) matematiksel inançları matematiğin doğası, matematik öğrenme ve matematik öğretme ile ilgili inançlar olarak üç kategoriye ayırmaktadır. McLeod (1992) ise öğrencilerin matematiksel inançlarını dört kategoriye ayırmaktadır: (i) matematik ile ilgili inançlar, (ii) öğrencinin kendisi ile ilgili inançlar, (iii) öğretim ile ilgili inançlar ve (iv) sosyal bağlam ile ilgili inançlar. Öğrencilerin matematiksel inançlarının alt kategorilere ayrılması (McLeod, 1992; Raymond, 1997) bu inançların parçalı bir şekilde araştırılmasına (Opt'y Eynde ve De Corte; 2004) neden olmuştur. Öğrencilerin matematiksel inançlarını araştıran çalışmalar (Kloosterman ve Cougan; 1994; Spangler, 1992; Schoenfeld, 1989) incelendiğinde, bu çalışmaların daha çok McLeod'un (1992) oluşturduğu matematiğin doğası ve öğrencinin kendisi/matematik öğrenme ile ilgili inançlar kapsamında ele alındığı görülmektedir.

Bunun yanında öğrenciler matematiği yalnızca sayı, işlem ve hesaplama olarak görmektedirler. Ezber yapmanın ise matematiği öğrenmenin ve matematikte başarılı olabilmenin temel bir yolu olduğuna inanmaktadırlar. Kimi öğrenciler matematiğin doğuştan gelen bir yetenek olduğuna ve zeki kişilerin matematikte başarılı olacağına inanırken, kimi öğrenciler ise çalışarak matematikte başarılı olunacağına inanmaktadırlar. Ayrıca öğrencilerin büyük çoğunluğu matematiğin yaşantıları için çok önemli ve faydalı olduğuna inanmaktadır (Schoenfeld, 1989; Southwell ve Khamis, 1994; Spangler, 1992; Kloosterman ve Cougan; 1994; Vanayan, White, Yuen ve Teper, 1997). Kislenko, Grevholm ve Lepik (2005) yaptıkları çalışmada öğrencilerin büyük çoğunluğunun matematiğin zor olduğuna ve bu nedenle çok çalışmanın gerekliliğine inandıkları sonucuna ulaşılmıştır. Ayrıca, öğrencilerin \% 86'sının matematiği önemli ve \% 65 'inin matematiği gerekli gördükleri ancak \% 48'inin ise matematiği sıkıcı buldukları tespit edilmiştir.

Öğrencilerin matematiksel inançları, matematik başarıları ve matematiksel yetenekleri (Kloosterman ve Cougan, 1994; Mason ve Scrivani, 2004; Schommer-Aikins, Duell ve Hutter, 2005; Suthar ve Tarmizi, 2010) ile davranışları ve karar vermeleri (Goldin, Rösken ve Törner, 2009; Kloosterman ve Cougan, 1994; Pajares, 1992) üzerinde önemli bir etkiye sahiptir. Matematik başarısı yüksek olan öğrenciler diğer öğrencilere göre matematiğe yönelik daha pozitif inançlar beslemektedirler. Aynı zamanda matematiği seven öğrencilerin de matematik başarıları oldukça yüksektir. Bu durum matematiksel inanç ve matematik başarısı arasındaki bu ilişkinin tek yönlü bir ilişki olmayıp çift yönlü bir ilişki olduğunu göstermektedir (Eleftherios ve Theodosios, 2007; Opt'y Eynde ve De Corte, 2004). İnançlar ile davranışlar ve karar verme arasında da benzer bir ilişki vardır. İnançlar, davranışların ve verilen kararların belirleyicisidir. Verilen etkili ve güçlü kararlar ise pozitif inançların oluşmasını sağlar. Benzer şekilde inançların, davranışlar ve verilen kararlar ile çift yönlü bir etkileşim içinde olduğu görülmektedir (Bandura, 1986; Goldin, Rösken ve Törner, 2009; White, Way, Perry ve Southwell, 2005, 2006).

Öğrencilerin inançları, öğrenme hedeflerini de etkilemektedir (Cobb, 1986). Öğrenme hedeflerinin ise öğrenmeler üzerinde önemli bir etkisi olduğu bilinen bir gerçektir. Bu durum, öğrencilerin sahip olduğu inançların öğrenmeleri üzerinde doğrudan veya dolaylı olarak etkili olduğunu göstermektedir. Bu alanda Kloosterman ve Cougan (1994) tarafından 1-6. sınıf öğrencileriyle yapılan çalışma sonucunda, matematiği seven öğrencilerin matematik öğrenmeye yönelik özgüvenlerinin yüksek, matematiği sevmeyen öğrencilerin ise oldukça düşük özgüvene sahip oldukları sonucuna ulaşılmıştır. Schoenfeld'un (1989) 10-12. sınıf öğrencileri ile yaptı̆̆ çalışma sonucunda ise öğrencilerin Öklidyen Geometri ile ilgili inançlarının öğrenmeleri sonucu oluştuğu görülmüştür. Araştırma sonuçları öğrencilerin matematiksel inançlarının ve öğrenmelerinin çift yönlü olarak birbirlerini etkilediklerini göstermektedir. Öğrencilerin öğrenme 
deneyimleri matematik ile ilişkili inançların oluşumunu ve var olan inançlar da bireyin yeni matematiksel deneyimlere yaklaşımını etkilemektedir. Bu durum inançlar ve öğrenmeler arasındaki ilişkinin döngüsel olduğunu ortaya koymaktadır (Spangler, 1992).

İnançlar doğaları gereği uzun sürede oluşan bilişsel yapılardır (McLeod, 1992) ve kişinin deneyimleri sonucu oluşur (Pehkonen ve Pietila, 2003). Öğrencilerin matematik hakkındaki inançları öğrenme süreci ile çok güçlü bir şekilde ilişkilidir (Opt’y Eynde ve De Corte, 2004). Öğrencilerin öğrenme sürecindeki matematik hakkındaki inançlarının oluşmasında ise öğretmenlerin büyük bir etkisi vardır (Lazim, Abu Osman ve Salihin, 2004). Wilkins ve Ma (2003) ilköğretim ve lise öğrencileri (7-12. sınıf) ile yaptıkları araştırma sonucunda, sınıf düzeyi ilerledikçe öğrencilerin inançlarında negatif bir değişim olduğunu bulmuştur. Ayrıca, öğretmen desteği ile öğrencilerin matematiksel inançları arasında pozitif bir ilişki olduğu tespit edilmiş ve öğretmen desteğini alan öğrencilerin olumsuz inançlarındaki artışın daha yavaş olduğu görülmüş̧ür.

Öğretmenlerin öğrencilerin matematiksel inançları üzerindeki güçlü etkisi öğretmenlerin sınıf içi rolünün önemini ortaya koymaktadır. Öğretmenler, öğrencilerin matematiksel inançlarını buna bağlı olarak da matematik başarılarını artırmaya yönelik olumlu öğrenme ortamları oluşturmalıdırlar (Tarmizi ve Tarmizi, 2010). Perkins, Adams, Pollock, Finkelstein ve Wieman (2004) çalışmalarında öğretim uygulamaları ve öğrencilerin inançları arasındaki ilişkiyi araştırmışlardır. Araştırma sonucunda, etkileşimli öğrenme yöntemlerin kullanıldığı ve kavramsal anlamaları destekleyen derslerin öğrencilerin inançlarını olumlu yönde etkilediği belirlenmiştir. Öğretmenlerin öğrencilerin matematiksel inançlarının farkında olmaları uygun öğrenme ortamları hazırlayabilmeleri ve öğrenme sürecini değerlendirebilmeleri açısından önemlidir (Kislenko, Grevholm ve Lepik, 2005; Spangler, 1992).

Türkiye'de yapılan çalışmalarda ise öğretmen ve öğretmen adaylarının (Bali, Kayhan ve Polat, 2004; Paksu, 2008) matematiğe yönelik inançlarının incelenmesine yönelik çalışmaların ağırlıkta olduğu görülmektedir. Buna karşın, ortaokul öğrencilerinin matematiğe yönelik inançlarını araştıran az sayıda çalışmayla (Kayaaslan, 2006; Uçar, Pişkin, Akkaş ve Taşçı, 2010) karşılaşılmıştır. Türkiye'de ortaokul öğrencilerinin matematiğe ilişkin olası farklı inançlarının belirlenmesi öğrencilerin matematik yaşantılarının daha iyi anlaşılabilmesi açısından önemli görülmektedir. Bu bağlamda öğrencilerin matematiksel inançlarını ortaya çıkaracak yeni çalışmalara ihtiyaç duyulmaktadır. Bu düşünceden hareketle, bu araştırmada ortaokul öğrencilerinin matematiğe ilişkin inançlarının belirlenmesi amaçlanmıştır.

\section{Yöntem}

$\mathrm{Bu}$ araştırma nitel araştırma yöntemi kullanılarak gerçekleştirilmiştir. Öğrencilerin matematiğe ilişkin inançlarının belirlenmesinin amaçlandığı bu araştırmada olgu bilim (fenomenoloji) deseni kullanılmıştır. Olgu bilim araştırmalarında temel amaç bireylerin bir olguya yönelik yaşanmış deneyimleri sonucu oluşturdukları anlamları ortaya koymaktır (Creswell, 2007). Bu araştırmada öğrencilerin matematiğe ilişkin inançları oluşturdukları metaforlar aracılığıyla belirlenmeye çalışılmıştır. Metafor bireyin bir olguyu başka bir olguya benzeterek açılaması olarak ifade edilebilir (Clarken, 1997).

\section{Çalışma Grubu}

Araştırmaya İç Anadolu Bölgesi'ndeki bir ilde iki farklı okulda öğrenim görmekte olan toplam 261 ortaokul (6, 7 ve 8. sınıf) öğrencisi katılmıştır. 9 öğrencinin formlarında yanıtlanmamış ve eksik ifadeler olduğu için bu öğrenciler çalışmaya dâhil edilmemiştir. Bu nedenle çalışma grubunu 252 öğrenci oluşturmuştur. Çalışma grubunun cinsiyet ve sınıf düzeylerine göre dağılımı Tablo 1.’de verilmiştir. 
Tablo 1. Çalışma Grubunun Özellikleri

\begin{tabular}{lcccc}
\hline $\begin{array}{l}\text { Cinsiyet/Sınıf } \\
\text { Düzeyi }\end{array}$ & 6. Sinıf & 7. Sinıf & 8. Sinıf & Toplam \\
\hline Kız & 44 & 39 & 46 & 129 \\
Erkek & 40 & 43 & 40 & 123 \\
Toplam & 84 & 82 & 86 & 252 \\
\hline
\end{tabular}

Verilerin Toplanması ve Analizi

Öğrencilerin matematiksel inançlarını ortaya çıkarmak amacıyla öğrencilere üç tane açık uçlu soru sorulmuştur. Öğrencilerden bu soruları yazılı olarak yanıtlamaları istenmiştir. Öğrencilere yöneltilen sorular aşağıda verilmiştir.

1. Matematiği bir renge benzetmen gerekirse hangi renge benzetirsin, neden?

2. Matematiği bir eşyaya benzetmen gerekirse hangi eşyaya benzetirsin, neden?

3. Matematiği bir hayvana benzetmen gerekirse hangi hayvana benzetirsin, neden?

Öğrencilerin bu soruları cevaplarken kullandıkları metaforlar ve bu metaforları seçme gerekçeleri kapsamında matematiğe ilişkin inançları belirlenmeye çalışılmıştır. Birinci soru ile öğrencilerin matematiğe yönelik olumlu veya olumsuz inançlarını açığa çıkarmak amaçlanmıştır. İkinci ve üçüncü sorular ile ise de öğrencilerin matematiksel inançlarını ve bu inançların farklı boyutlarını açığa çıkarmak amaçlanmıştır.

Toplanan verilerin analizinde içerik analizi kullanılmıştır. Öğrencilere sorulan her bir sorudan elde edilen veriler ayrı olarak analiz edilmiştir. Verilerin analizinde (i) verinin düzenlenmesi, (ii) verinin kodlanması, (iii) taslak temaların belirlenmesi, (iv) taslak temalara göre kodların düzenlenmesi, (v) taslak temaların kontrol edilmesi ve kesinleştirilmesi ve (vi) kodlara ve temalara göre verilerin betimlenmesi, açılanması ve yorumlanması (Collins, 1999; Akt. Yıldırım ve Şimşek, 2011) aşamaları izlenmiştir. Araştırmanın güvenirliğini sağlamak için verilerin kodlanması iki kodlayıcı tarafından eş zamanlı olarak gerçekleştirilmiştir. Kodlayıcılar arası tuttarlı1ık \% 95 bulunmuştur. Kodların oluşturulmasında ilgili alan yazından faydalanılmamış, kodlar doğrudan veriden üretilmiştir. Kodlama sonrası oluşturulan her bir tema için öğrenci sayıları ve yüzdeleri hesaplanmıştır.

\section{Bulgular}

Öğrencilerin sorulara verdikleri yanıtlar sonucu elde edilen bulgular her bir soru için ayrı olarak verilmiştir.

“Matematiği Bir Renge Benzetmen Gerekirse Hangi Renge Benzetirsin, Neden?” Sorusuna İlişkin Bulgular

Öğrencilerin bu soruya verdikleri yanıtlara göre matematiğe yönelik inançları olumlu, olumsuz ve olumlu/olumsuz olmak üzere üç kategoriye ayrılmışır. Tablo 2. bu kategorilerdeki öğrenci sayılarını, yüzdelerini ve ifadelerini göstermektedir. 
Tablo 2. Öğrencilerin Matematiğe Yönelik İnançları

\begin{tabular}{|c|c|c|c|}
\hline İnanç & $\mathbf{F}$ & $\%$ & Öğrencilerin Kullandıkları İfadeler \\
\hline Olumlu & 169 & 69 & $\begin{array}{l}\text { eğlence, neşe, kıpır kıpır, renkli, güzel, sıcak, sevgi, huzur, } \\
\text { mutluluk, umut, canlı, aydınlık-1şık, asalet, büyüklük, bilgi, } \\
\text { düzen, yararlı, anlaşılır, temiz, sonsuzluk }\end{array}$ \\
\hline Olumsuz & 54 & 23 & $\begin{array}{l}\text { zor, karışık, karamsar, mutsuzluk, kabus, hüzün, sıkıcı, } \\
\text { soğuk, solgun, karanlık }\end{array}$ \\
\hline $\begin{array}{l}\text { Olumlu ve } \\
\text { Olumsuz }\end{array}$ & 19 & 8 & $\begin{array}{l}\text { iyi-kötü, eğlenceli-sıkıcı, mutlu-mutsuz, aydınlık-karanlık, } \\
\text { çok anlamlılık, gizemli }\end{array}$ \\
\hline
\end{tabular}

Öğrencilerin \% 69'unun matematik ile ilgili olumlu, \% 23'ünün olumsuz ve \% 8'inin ise hem olumlu hem de olumsuz inançlara sahip oldukları görülmektedir.

Matematik hakkında olumlu inanç besleyen öğrenciler matematiğin eğlenceli olduğunu, insanı mutlu ettiğini, bilgi vererek insanları aydınlattığını ve geleceğe 1şık tuttuğunu belirtmişlerdir. Ayrıca matematiğin düzenli, yararlı ve anlaşılır olduğunu ifade etmişlerdir. Matematik hakkında olumsuz inanç besleyen öğrenciler ise matematiğin insanın içini kararttığını, mutsuz ettiğini, çok karışık, sıkıcı ve zor olduğunu belirten ifadeler kullanmışlardır. Öğrencilerin \% 8'i ise olumlu ve olumsuz ifadeleri bir arada kullanmışlardır. Tablo 3. öğrencilerin matematiği benzettikleri renklerin kategorilere dağılımını göstermektedir.

Tablo 3. Öğrencilerin Matematiği Benzettikleri Renklerin Kategorilere Göre Dă̆ıllımları

\begin{tabular}{|c|c|c|c|c|c|c|c|c|}
\hline \multicolumn{3}{|c|}{ Olumlu İnanç } & \multicolumn{3}{|c|}{ Olumsuz İnanç } & \multicolumn{3}{|c|}{ Olumlu ve Olumsuz İnanç } \\
\hline Renk & $f$ & $\%$ & Renk & $f$ & $\%$ & Renk & $f$ & $\%$ \\
\hline Beyaz & 41 & 24,3 & Siyah & 50 & 92,5 & $\begin{array}{l}\text { Tüm } \\
\text { renkler }\end{array}$ & 10 & 52,6 \\
\hline Mavi & 36 & 21,3 & Mavi & 2 & 3,7 & Gri & 5 & 26,3 \\
\hline Yeşil & 23 & 13,6 & Kırmızı & 1 & 1,9 & Kırmızı & 3 & 15,8 \\
\hline Sar1 & 22 & 13 & Kahve & 1 & 1,9 & Siyah & 1 & 5,3 \\
\hline Kırmiz1 & 20 & 11,8 & & & & & & \\
\hline Mor & 16 & 9,5 & & & & & & \\
\hline Pembe & 11 & 6,5 & & & & & & \\
\hline
\end{tabular}

Matematiğe yönelik olumlu inançlara sahip öğrenciler matematiği en çok beyaz (\% 24,3) ve mavi $(\% 21,3)$ renge benzetmişlerdir. Beyaz ve mavi dışında öğrenciler yeşil, sarı, kırmızı, mor ve pembe renklerini ifadelerinde kullanmışlardır. Öğrencilerin olumlu ifadelerini belirtirken daha çok açık renkleri tercih ettikleri görülmektedir. Bazı öğrenci ifadeleri aşağıda örnek olarak verilmiş̧ir.

"Beyaza benzetirim çünkü matematik benim için aydınlıktır ve gelecek ışlğıdır."

"Matematik de beyaz gibi açık ve anlaşılırdır."

"Mor renk çünkü asaletin ve büyüklügün rengidir." 
"Sarı çünkü güneş gibi matematik de ışıl ışıl parlıyor, güneş her tarafı matematik biz nesilleri aydınlatıyor."

Matematiğe yönelik inançları olumsuz olan öğrencilerin \% 92'si matematiği siyah renge benzetmişlerdir. Çok az sayıda öğrenci ise mavi, kırmızı ve kahve renklerini ifadelerinde kullanmışlardır. Öğrenci açıklamaları aşağıda örnek olarak verilmiştir.

"Siyah çünkü insanın içini karartıyor ve insanı mutsuz ediyor, insanın ondan uzak durası geliyor... Kâbus gibi... Matematikte siyah renk gibi gittikçe karanlı̆̆ın içinde kayboluyorsun."

"Siyah renge benzetmek isterdim çünkü matematik içinde barındırdı̆̆ çıkaramayacak kadar siyahtır."

Matematiğe yönelik hem olumlu hem olumsuz görüş belirten öğrencilerin \% 52'si matematiği tüm renklere benzetmişlerdir. Öğrenciler matematiğin kimi zaman çok zevkli kimi zaman ise çok sıkıcı bir ders olduğunu belirtmişlerdir. Bir öğrenci renkler arasında solgun ve canlı renklerin bulunması gibi matematik dünyasının da hem solgun hem renkli olduğunu söylemiştir. Öğrencilerin \% 26's1 ise matematiğin siyah kadar karanlık, beyaz kadar ise aydınlık olmadığı için griye benzediğini ifade etmişlerdir. Aşağıda bu yöndeki öğrenci görüşlerinden alıntılar verilmiştir.

"Bütün renklere benzetirdim, çünkü her bir renk insanda farklı duygular yaratır ve matematik de öyledir..."

"Griye benzetirim bazen derslerim iyi, eğlenceli geçer, bazen de konuyu anlayamadığım için mutsuz geçer. İşte bu yüzde ne siyaha ne beyaza benzetiyorum bence en uygunu gridir."

“Kırmızı çünkü kırmızı bana göre iyi ve kötü arasında kalan bir renktir."

"Matematiği Bir Eşyaya Benzetmen Gerekirse Hangi Eşyaya Benzetirsin, Neden?” Sorusuna İlişkin Bulgular

Öğrencilerin matematiği hangi eşyaya benzettikleri kodlanmıştır. Öğrencilerin seçtikleri eşyaları neden matematiğe benzettikleri ile ilgili yaptıkları açıklamalar ise belli temalar altında toplanmıştır. Öğrencilerin matematiği benzettiği eşyalar, oluşan temalar, öğrenci sayıları ve yüzdeleri Tablo 4.' te verilmiştir.

Tablo 4. Temalara Göre Öğrencilerin Dă̆ılımı

\begin{tabular}{|c|c|c|c|c|c|}
\hline Tema & $f$ & $\%$ & & ullanılan Metafor & \\
\hline & & & Bilgisayar $(\% 29,3)$ & Telefon $(\% 6,1)$ & \\
\hline & & & Kitap $(\% 18,3)$ & Hesap makinesi & Kumbara $(\% 1,2)$ \\
\hline $\begin{array}{l}\text { MatematıK } \\
\text { hiloi }\end{array}$ & 82 & 33 , & Dolap $(\% 14,6)$ & $(\% 3,7)$ & Kutu $(\% 1,2)$ \\
\hline b1lg1 & 02 & 9 & Yaz1 tahtas1 $(\% 7,3)$ & Defter $(\% 2,4)$ & Satranç $(\% 1,2)$ \\
\hline & & & Televizyon $(\% 7,3)$ & Küp $(\% 1,2)$ & Tablo $(\% 1,2)$ \\
\hline & & & & Kütüphane $(\% 1,2)$ & \\
\hline $\begin{array}{l}\text { Matematik } \\
\text { sayılar ve } \\
\text { işlemlerdir }\end{array}$ & 60 & $\begin{array}{c}24, \\
8\end{array}$ & $\begin{array}{l}\text { Hesap makinesi } \\
(\% 80) \\
\text { Saat }(\% 8,3)\end{array}$ & $\begin{array}{l}\text { Abaküs }(\% 6,7) \\
\text { Bilgisayar }(\% 4,9)\end{array}$ & \\
\hline
\end{tabular}




\begin{tabular}{|c|c|c|c|c|c|}
\hline $\begin{array}{l}\text { Matematik } \\
\text { gereklidir }\end{array}$ & 23 & 9,5 & $\begin{array}{l}\text { Ayakkabı }(\% 21,7) \\
\text { Kalem }(\% 17,4), \\
\text { Televizyon }(\% 17,4)\end{array}$ & $\begin{array}{l}\text { Çanta }(\% 17,4) \\
\text { Para }(\% 13,3) \\
\text { Altın }(\% 4,3)\end{array}$ & $\begin{array}{l}\text { Bavul }(\% 4,3) \\
\text { Kişisel eşya }(\% 4,3)\end{array}$ \\
\hline $\begin{array}{l}\text { Matematik } \\
\text { zor ve } \\
\text { karışıktır }\end{array}$ & 21 & 8,7 & $\begin{array}{l}\text { Küp }(\% 28,5) \\
\text { Yapboz }(\% 23,8)\end{array}$ & $\begin{array}{l}\text { Zincir }(\% 19) \\
\text { Bilgisayar } \\
(\% 14,3)\end{array}$ & $\begin{array}{r}\text { robotu } \\
\text { makinesi }\end{array}$ \\
\hline $\begin{array}{l}\text { Matematik } \\
\text { yol } \\
\text { göstericidir }\end{array}$ & 12 & 5 & $\begin{array}{l}\text { Pusula }(\% 66,7) \\
\text { Harita }(\% 16,6) \\
\text { Dürbün }(\% 8,3) \\
\text { Mercek }(\% 8,3)\end{array}$ & & \\
\hline
\end{tabular}

Matematik bilgi vericidir. Öğrencilerin \% 33,9'unun matematiği bilgi verici olarak gördükleri tespit edilmiştir. Matematiği bilgi verici olarak tanımlayan öğrencilerin bilgisayar (\% 29,3), kitap $(\%$ 18,3) ve dolap (\% 14,6) benzetmelerinin yüksek bir oranda olduğu görülmektedir. Öğrenciler bilgisayar ve kitaptaki gibi matematikte de birçok bilgi olduğunu vurgulamışlardır. Dolap benzetmesinde bulunan öğrenciler ise matematiğin birçok bilgiyi sakladığını belirtmişlerdir. Aşağıda bu yöndeki öğrenci açıklaması verilmiştir.

"Dolaba benzetirim. Çünkü matematik içinde birçok şeyi barındırır, bize ögretir."

Bir öğrenci matematiği kumbaraya benzetmiştir. Bu öğrenci "her gün bir bilgi öğreniyoruz ve kumbaraya atıyoruz" şeklinde açıklama yapmıştır. Başka bir öğrenci ise kütüphanedeki bilgiler gibi matematikte de sonsuz bir bilgi olduğunu söylemiştir. Yazı tahtası benzetmesinde bulunan bir öğrencinin aşağıdaki ifadesi dikkat çekicidir.

"Yazı tahtasına yazıları yazarız ve gerekmediği sürece sileriz. İnsan beyninin matematikle ilgisi aynen böyledir."

Matematik saylar ve işlemlerdir/Matematik hesaplama yapmaktır. Öğrenci açıklamaları incelendiğinde öğrencilerin \% 24,8'inin matematik için sayı, işlem ve hesaplama ifadelerini kullandıkları görülmüştür. Matematiği sayı, işlem ve hesaplama olarak tanımlayan öğrencilerin \% 80'i matematiği hesap makinesine benzetmişlerdir. Aşağıda bu yöndeki öğrenci açıklaması verilmiştir.

"Hesap makinesine benzetirim çünkü matematik işlemle ilgilidir ve hesap makinesi gibi her şeyi hesaplar."

Beş öğrenci saatteki sayılar gibi matematiğin de sayılarla ilişkili olduğunu ifade etmiştir. Abaküs benzetmesinde bulunan dört öğrenci ise abaküsün işlem yapabilme özelliğini vurgulamıştır. Üç öğrenci açıklamalarında matematikte de bilgisayardaki gibi işlem yapıldığını belirtmiştir. Öğrenci açıklamalarına bakıldığında öğrencilerin matematiği sayılar ve işlemlerle hesaplama yapmak olarak algıladıkları söylenebilir.

Matematik gereklidir. Öğrencilerin \% 9,5'i matematiğin gerekli olduğuna inanmaktadırlar. Beş öğrenci ayakkabı olmadan bir şey yapılamayacağı gibi matematik olmadan da bir şey yapılamayacağı yönünde görüş bildirmiştir. Aşağıdaki öğrenci açıklaması bu duruma bir örnektir.

“Ayakkabıya benzetirim çünkü ayakkabılarımız olmadan yürüyemeyiz. İşte matematik olmadan da hayatımıza devam edemeyiz." 
Bazı öğrenciler matematiğin para, kalem ve çanta kadar günlük hayatta gerekli olduğunu söylemiştir. Bir öğrenci ise matematik için "Kişisel eşyalarım kadar gerekli ve değerli" şeklinde açılama yapmıştır. Altın ve bavul benzetmesinde bulunan öğrencilerin ifadeleri ise "Nereye götürürsek götürelim işimize yarar, ihtiyaç duyarız” yönündedir.

Matematik zor ve karışıktır. Öğrencilerin \% 8,7'si matematiğin zor ve karışık olduğunu ifade etmişlerdir. $\mathrm{Bu}$ öğrencilerin matematiği benzettikleri eşyalar arasında küp (\% 28,5), yapboz (\% 23,8) ve zincirin (\% 19) yüksek oranda olduğu görülmektedir. Öğrenciler matematiğin küp kadar karışık olduğunu söylemişlerdir. Ayrıca, bazı öğrenciler küp gibi matematiğinde içerisini görmenin zor olduğunu ifade etmişlerdir. Zincir ve yapboz benzetmesinde bulunan öğrenciler ise yapbozun parçaları ve zincirin halkaları gibi matematiğin de çok karışık olduğunu belirtmişlerdir. Aşağıdaki ifadeler öğrencilerin bu yöndeki inançlarını yansıtmaktadır.

\section{"Zincire benzetirim çünkü matematik problemlerini çözmek zincirin halkalarını birbirinden ayırmak kadar zor ve halkalardan biri koparsa sorunun cevabını bulamazsın."}

"Yapboz çünkü yapbozda parçalar çok karışıktır ve bunları birleştirmek çok zordur."

İki öğrenci matematiğin mutfak robotu gibi insanı parçaladığını söylemiştir. Bulaşık makinesi benzetmesini kullanan bir öğrenci ise "Birçok işlem yaparak kafamızı bulandırıyor" açıklamasında bulunmuştur.

Matematik yol göstericidir. Öğrencilerin \% 5' inin matematiğin yol gösterici olduğuna inandıkları görülmüştür. Matematiği pusulaya $(\% 66,9)$ ve haritaya $(\% 16,6)$ benzeten öğrenciler "Matematik sayesinde yolumuzu buluruz" şeklinde açıklama yapmışlardır. İki öğrenci ise dürbün ve mercekteki olduğu gibi matematiğin istenilen şeyleri daha ayrıntılı görme imkânı sağladığını belirtmiştir.

On öğrenci $(\% 4,1)$ matematik için “Buzdolabı gibi soğuk, insanı okuldan ve derslerden soğutur” benzeri ifadeler kullanmıştır. Matematiği gereksiz bir eşya olarak betimleyen altı öğrenci $(\% 2,5)$ ise matematiğe hiçbir yerde ihtiyaç duyulmayacağını belirtmiştir. Aşağıdaki verilen öğrenci ifadesi bu durumu yansitmaktadir.

\section{"Ben şahsen matematiği gereksiz bir eşyaya benzetiyorum. Çünkü atsan atılmaz satsan} satılmaz. Kim alır ki zaten, mesela çöp kutusu."

Bir öğrenci "Matematik evrensel olduğu için saate benzetiyorum” şeklinde bir açıklamada bulunmuştur. Ayrıca matematiğin sürekli ilerleyen bir alan olduğunu belirten bir diğer öğrenci ise bisiklet benzetmesinde bulunmuştur. Matematiği futbol topuna benzeten bir öğrencinin ifadesi dikkat çekicidir.

"Matematiği futbol topuna benzetirim. Her topa vurduğumda matematiğin act çekmesini isterim böylece de çok mutlu olurum."

Yukarıda belirtilenler dışında öğrenciler açıklamalarında canavar heykeli, oyun, dikiş makinesi, dünya, altın, terazi, çikolata, pergel ve cetvel benzetmelerinde bulunmuşlardır.

“Matematiği Bir Hayvana Benzetmen Gerekirse Hangi Hayvana Benzetirsin, Neden?” Sorusuna İlişkin Bulgular

Öğrencilerin bu sorudaki "neden?” sorusuna yönelik verdikleri yanıtlar matematiğe ilişkin düşüncelerini açıklayan belli temalar altında toplanmıştır. Bu kapsamda matematiği benzettikleri hayvanlar bulgu olarak kullanılmamıştır. Tablo 5. oluşan bu temalardaki öğrenci sayılarını ve yüzdelerini göstermektedir. 
Tablo 5. Temalara Göre Öğrenci Sayıları ve Yüzdeleri

\begin{tabular}{lll}
\hline Tema & $f$ & \% \\
\hline Matematik akıl ve zekâ gerektirir. & 67 & 27,7 \\
Matematikte başarılı olmak için çok çalışmak gereklidir. & 37 & 15,3 \\
Matematik ezber ve tekrarla gelişir. & 33 & 13,6 \\
Matematik zor ve karışıtır. & 28 & 11,6 \\
Matematik yararlıdır, hayatı kolaylaştırır. & 22 & 9,1 \\
Matematik güzel ve eğlencelidir. & 19 & 7,9 \\
Matematik iletişim kurmaya yardımcı olur. & 18 & 7,4 \\
\hline
\end{tabular}

Matematik akıl ve zekâ gerektirir. Öğrencilerin \% 27,7'si matematikte başarılı olmak için akıl ve zekânın gerekli olduğunu belirtmişlerdir. Ayrıca, çoğu öğrenci matematikte düşünme, anlama ve planlamanın önemini vurgulamıştır. Aşağıda bir öğrencinin açıklaması verilmiştir.

"Çünkü akıllı ve zeki olanlar matematikte başarılı olurlar. Matematik zeki olanlar için zor değildir."

Matematikte başarılı olmak için çok çalışmak gereklidir. Öğrencilerin \% 15,3'ü matematikte başarılı olmak için çok çalışmak gerektiğine inanmaktadırlar. Bu öğrencilerden bazıları açıklamalarında "çaba, emek, sabır, dikkat" sözcüklerini kullanmışlardır. İki öğrenci matematik dersinde başarılı olan öğrencilerin sınıfın en çalışkanları olduklarını belirtmiştir. Beş öğrenci ise zeki olmadan da çalışarak matematikte başarılı olunabileceğini söylemiştir. Aşağıda iki öğrencinin ifadeleri yer almaktadır.

\footnotetext{
"Karıncaya benzetirim çünkü karınca çalı̧̧kan bir hayvandır ve matematikte zorlukları çalışarak ve yürüyerek başarabilirsin."

"Arıya benzetirim çünkü durmadan çalışmak gerekir ve çalıştıkça bir şeyler üretilir."
}

Matematik ezber ve tekrarla gelişir. Ezber ve tekrarın önemli olduğunu vurgulayan öğrencilerin (\% 13,6) büyük çoğunluğu matematik formüllerini ve sembollerini ezberlenmesi gerektiğini; formül ve sembolleri unutmamak için ise sürekli tekrar yapılması gerektiğini ifade etmişlerdir. Altı öğrenci ise matematikte soru ve problemleri daha iyi çözebilmek için tekrarın önemli olduğunu belirtmiştir. Bir öğrencinin yaptığı benzetme örnek olarak verilmiştir.

"Papağana çünkü çoğu şeyi ezberliyor, matematik de tekrar yaparak gelişir."

Matematik zor ve karışıktır. Öğrencilerin \% 11,6'sı matematik için "karışık, karmaşık, karmakarışık, zor, dikenli, vahşi ve yırtıcl" betimlemelerini kullanmışlardır. Öğrenciler matematiğin zor ve karışık olduğu için başarılı olmanın da çok zor olduğuna inanmaktadırlar. Aşağıdaki öğrenci ifadeleri bu durumu yansitmaktadir.

\footnotetext{
"Bir aslana benzetirim çünkü vahşi ve yırtıcıdır ve onu yenmek çok zordur. "Matematiği ögrenmek de bir aslant yakalamak kadar zordur."

"Bukalemuna benzetirim çünkü hayatı çok karışıktır, her renge bürünür."
} 
Bir öğrenci ise matematiğin leylek sürüsü kadar karışık ve kırkayağı saymak kadar zor olduğunu söylemiştir. Başka bir öğrenci ise matematik için "Her gördügünü avlayan, kafasını karıştıran ve sonra da onu delirtip yok eden bir çeşit virüs" benzetmesi yapmıştır.

Matematik yararlıdır, hayatı kolaylaştırır. Öğrencilerin \% 9,1'i matematiğin karş1laşılan problemlere çözüm bulduğu, planlı ve pratik düşünmeyi sağladığı için hayatı kolaylaştırdığını ifade etmiştir. Ayrıca dört öğrenci matematik sayesinde zamanın daha verimli kullanıldı̆̆ını söylemiştir. Üç öğrenci ise diğer bilimlerin matematik sayesinde geliştiğini ek olarak ifade etmiştir. Öğrencilerin matematiğin birçok alanda kullanılarak insanlara yararlı olduğuna inandıkları söylenebilir. Aşağıda bir öğrencinin açıklaması verilmiştir.

\section{"Matematiği kuşa benzetiyorum çünkü kuşlar birçok böcek türünü yiyerek hayatımızı birçok zararlı böcekten kurtarır, matematikte hayatımızı kolaylaştırır."}

Matematik güzel ve eğlencelidir. Öğrencilerin \% 7,9'u matematiğin güzel bir ders ve matematik ile uğraşmanın ise eğlenceli olduğu yönünde açıklama yapmışlardır. $\mathrm{Bu}$ yönde görüş bildiren öğrenciler matematiğin insanı neşelendirdiğini, umutlandırdığını, mutlu ettiğini ve hayata canlılık kattığını söylemişlerdir. Bir öğrenci ise "matematiğin içerisinde bir sonsuzluk barındırdlğını ve bu sonsuzluğun kişiye huzur verdiğini" belirtmiştir. Matematikte problem çözmenin bambaşka bir eğlence olduğunu söyleyen bir öğrenci sorunun çözümüne ulaşmak için heyecanlandığını ifade etmiştir.

Matematik iletişim kurmaya yardımcı olur. Öğrencilerin \% 7,4'ü matematiği bir “iletişim dili ve iletişim aracı " olarak tanımlamışlardır. Bu öğrenciler matematik sayesinde iletişim kurmanın daha da kolaylaştığını vurgulamışlardır. Bir öğrenci matematik dersindeki iletişimin diğer derslerdekinden farklı olduğunu belirtmiş ve "matematiksel iletişim" olarak tanımlamıştır. Öğretmenin ise matematiksel bir dille konuştuğunu eklemiştir. Başka bir öğrencinin bu yöndeki açıklaması ise şu şekildedir.

"Kuşa benzetirim çünkü kuşların kendine özgü bir dili vardır ve bu dil sayesinde iletişim kurarlar. Matematiğin ve matematikçilerin de ayrı bir dili vardır ve kendi aralarında bu dili kullanarak anlaşırlar, bu sayede de matematik gelişir."

Belirlenen temalar dışında on sekiz öğrenci farklı benzetmelerde bulunmuşlardır. Altı öğrenci matematiğin çok hızlı ilerleyen bir alan olduğunu ve günden güne geliştiğini ifade etmiştir. Matematiğin çok geniş bir alan olduğunu söyleyen beş öğrenci ise matematiğin içinde birçok konu bulunduğunu belirtmiştir. Bu öğrencilerden biri matematik için “enginlere slğmayan bir deniz” benzetmesi yapmıştır. Başka bir öğrenci ise ağacın dallarını matematikteki konulara benzetmiştir. Üç öğrenci ise "matematik derslerin kralıdır" şeklinde açıklama yapmıştır.

\section{Tartışma ve Sonuç}

$\mathrm{Bu}$ araştırmada ilköğretim 6,7 ve 8. sınıf öğrencilerinin matematiksel inançları tespit edilmeye çalışılmıştır. Öğrencilerin büyük çoğunluğu matematiği bilgi verici olarak tanımlamışlardır. Ayrıca öğrenciler matematiğin gerekli ve yararlı olduğunu, hayatı kolaylaştırdığını ifade etmişlerdir. Öğrencilerin bu görüşleri önceki çalışmaların bulgularıyla da paralellik göstermektedir (Kayaaslan 2006; Kislenko, Grevholm ve Lepik; 2005). Kloosterman ve Cougan (1994) öğrencilerin matematiğin yararlı olduğu yönündeki inançlarının her zaman açıklayıcı ve anlaşılır olmadığını belirtmişlerdir. Kayaaslan (2006) ise öğrencilerin matematiğinin günlük hayatta kullanımıyla ilgili inançlarının kuvvetlendirilmesi gerektiğini vurgulamıştır. $\mathrm{Bu}$ çalışmada da matematiğin neden yararlı ve gerekli olduğuna dair öğrencilerin yaptıkları açıklamaların 
oldukça yüzeysel olduğu görülmüştür. Öğrencilerin matematiğin yararlıllı̆ına inanmaları matematiksel öğrenmeleri açısından önemlidir. Ancak bu inançların daha açıklayıcı ve güçlü olması öğrenme sürecinin etkililiğinin artmasını sağlayacaktır. Öğretmenlere bu hususta ciddi sorumluluklar düşmektedir. Öğretmenler matematiğin gerekliliği, yararlılığı ve günlük hayatta kullanımına yönelik sınıf içi öğrenme ortamları oluşturmalıdırlar. Bu tür öğrenme ortamları öğrencilerin inançlarını içselleştirmelerine katkıda bulunacaktır.

Elde edilen önemli bulgulardan bir diğeri ise öğrencilerin yaklaşık dörtte birinin matematiği sayılar ve işlemler olarak tanımlamalarıdır. Ayrıca öğrenciler matematikte ezber ve tekrarın önemli olduğunu belirtmişlerdir. Öğrencilerin matematiğin sadece sayılar ve işlemlerden oluştuğuna ve ezberin önemli olduğuna inanmaları önceki çalışmalarda da en çok karşılaşılan bulgulardan biridir (Kayaaslan, 2006; Schoenfeld, 1989; Southwell ve Khamis, 1994; Spangler, 1992; Vanayan, White, Yuen ve Teper, 1997). Öğrenci ifadeleri öğrencilerin kuralları ve formülleri ezberleyerek matematikte başarılı olunacağına inandıklarını göstermektedir. Spangler (1992) öğrencilerin bazı kuralları ezberleyerek, anlamadan da doğru cevabı elde ettiklerini belirtmektedir. Bu nedenle öğrencilerin bir problemin çözümünde uygun kural kullanımının değil kavramsal anlamanın gerekli olduğuna inanmaları önem taşımaktadır (Kloosterman ve Cougan, 1994). Matematiksel ifadelerin doğasına yönelik ve kavramsal anlamlandırmayı ön plana çıkaran sınıf içi tartışmalar, öğrencilerin matematiğin yalnızca hesaplama ve ezbere dayanmadığına inanmalarını sağlamada önemlidir.

Dikkat çekici bir diğer bulgu ise, öğrencilerin yaklaşık dörtte birinin matematiğin akıl ve zekâ gerektirdiğini ifade etmesidir. Öğrenciler zeki olanların matematikte başarılı olabileceklerini belirtmişlerdir. Bazı öğrenciler ise matematiğin "doğuştan gelen bir yetenek" olduğunu ayrıca vurgulamışlardır. Öğrencilerde matematiğe yönelik böyle bir inancın oluşması üzerinde durulması gereken önemli bir konudur. Öğrencilerin \%15,3'ü ise başarı için çalışmanın önemli olduğunu belirtmişlerdir. Schoenfeld'in (1989) araştırma sonuçları öğrencilerin matematikte başarılı olmak için çok çalışmanın yetenekten daha önemli olduğuna ve başarının çok çalışma sonucu oluştuğuna inandıklarını göstermektedir. Öğrencilerdeki "ne kadar çalışsam da yapamıyorum” inancı giderilmeye çalışılmalıdır. Eğer öğrenciler çalışarak matematikte başarılı olacaklarına inanırlarsa matematik öğrenmeye daha istekli olacaklardır. Öğrencilerin bu yöndeki inançlarının kuvvetlendirilmesi gerekmektedir.

İkinci soruda öğrencilerin \% 8,7'sinin ve üçüncü soruda öğrencilerin \% 11,6'sının matematiği sıkıcı, zor ve karışık olarak tanımladıkları görülmüştür. Bu öğrenciler açıklamalarında "karışık, sıkıcı, zor, dikenli, vahşi ve yırtıcı" gibi ifadeleri kullanmışlardır. Öğrencilerin \% 7,9'u ise matematiği güzel ve eğlenceli olarak ifade etmişlerdir. Öğrencilerin matematik hakkındaki benzer inançlarının diğer çalışmaların bulgularıyla da benzerlik gösterdiği tespit edilmiştir (Kislenko, Grevholm ve Lepik, 2005; Schoenfeld, 1989; Uçar, Pişkin, Akkaş ve Taşçı, 2010).

Öğrencilerin \% 7,4'ü ise matematiği bir iletişim aracı olarak tanımlamışlardır. Öğrenciler açıklamalarında matematiksel bir dili vurgulamışlardır. Matematiğin bir dili olduğu kabul gören yaygın bir yargıdır. Matematik kavramlarıyla düşünebilmek ve çevredeki olaylara matematiksel anlamlar yükleyebilmek için matematik dili bilinmelidir (Umay, 2007). Bu nedenle, öğrencilerin matematiksel bir dilin farkında olmaları bu dili kullanabilmeleri bakımından önemlidir.

Öğrencilerin "matematiği bir renge benzetmek gerekirse hangi renge benzetirsin, neden?" sorusuna verdikleri yanıtların öğrencilerin matematiğe yönelik olumlu veya olumsuz inançlarını açığa çıkardığı görülmüştür. Öğrencilerin \% 69'unun matematiğe yönelik inançlarının olumlu, \% 23'ünün olumsuz ve \% 8 'inin ise hem olumlu hem de olumsuz olduğu tespit edilmiştir. Öğrencilerin büyük çoğunluğunun 
matematik hakkında olumlu inançlara sahip iken olumsuz inançlara sahip öğrencilerin az sayıda olduğunu söylemek oldukça güçtür. Bu öğrencilerin oldukça keskin inançlara (zor, kâbus, hüzün, sıkıcı, karamsar) sahip oldukları görülmüştür. Öğrencilerin bu inançları matematiğe ve matematiksel görevlere yaklaşımlarına (Garofalo, 1989), ayrıca sınıf içindeki öğrenme ortamıyla etkileşimlerine (Opt'y Eynde ve De Corte, 2004) yön veren önemli bir etkiye sahiptir. Bu durum öğrencilerin olumsuz inançlarının değiştirmenin ve olumlu inançlarının kuvvetlendirilmesinin etkili bir öğrenme süreci oluşturmadaki gerekliliğini ortaya koymaktadır. Bu hususta öğretmenlere önemli görevler düşmektedir.

$\mathrm{Bu}$ araştırmada ortaokul öğrencilerinin matematiksel inançları belirlenmeye çalışılmıştır. Öğrencilerin sahip oldukları bu inançların ve sebeplerinin derinlemesine araştırıldığı yeni çalışmalara ihtiyaç duyulmaktadır. Ayrıca ilköğretim düzeyinde bu inançların sınıf düzeyinde farklılaşıp farklılaşmadığını ve bunun sebeplerini inceleyen araştırmaların yapılması önemli görülmektedir.

\section{Kaynaklar}

Bali, G., Kayhan, M. ve Polat, Z. S. (2004). Okul öncesi matematik ögretmen adaylarının matematik hakkındaki inançları. Matematik Etkinlikleri Sempozyumu, 5-7 Mayıs 2004, Ankara: Milli Kütüphane.

Bandura, A. (1986). Social foundations of thought and action: A social cognitive theory. Englewood Cliffs, NJ: Prentice-Hall.

Clarken, R. H. (1997). Five metaphors for educators. Paper presented at the Annual Meeting of the American Educational Research Association, Chicago, March 24- 28.

Cobb, P. (1986). Contexts, goals, beliefs and learning mathematics. Journal for the Learning of Mathematics, 6(2), 2-9.

Creswell, J. W. (2007). Qualitative inquiry and research design: Choosing among five traditions. Thousand Oaks, CA: Sage Publications.

Eleftherios, K. \& Theodosios, Z. (2007). Students'beliefs and attitudes about studying and learning mathematics. Proceedings of the 31st Conference of the International Group for the Psychology of Mathematics Education, 3, 97-104.

Garofalo, J. (1989). Beliefs and their influence on mathematical performance. Mathematics Teacher, 82, 502-505.

Goldin, G. A. (2002). Affect, meta-affect, and mathematical belief structures, In G. Leder, E. Pehkonen, \& G. Törner (Ed.), Beliefs: A hidden variable in mathematics education? (pp. 59-72). Dordrecht: Kluwer Academic Publishers.

Goldin, G., Rösken, B. \& Törner, G. (2009). Beliefs - no longer a hidden variable in mathematical teaching and learning process. In Mabb, J., \& Schlöglmann, W. (Ed.), Beliefs and sttitudes in mathematics education (pp. 1-18). Rotterdam, Sense Publishers.

Kayaaslan, A. (2006). Illköğretim 4. ve 5. sinuf ögrrencilerinin matematiğin doğası ve matematik öğretimi hakkındaki inançları. Yayımlanmamış Yüksek Lisans Tezi, Gazi Üniversitesi, Ankara. 
Kislenko, K., Grevholm, B. \& Lepik. (2005). Mathematics is important but boring: Students' beliefs and attitudes toward mathematics. Paper presented to Fourth Nordic Conference on Mathematics Education, Trondheim, 2nd-6th September.

Kloosterman, P. \& Cougan, M. C. (1994). Students' beliefs about learning school mathematics. The Elementary School Journal, 94(4), 375-388.

Lazim, M. A., Abu Osman, M. T. \& Salihin. W. (2004). The statistical evidence in describing the students' beliefs about mathematics. International Journal for Mathematics Teaching and Learning, 6(1), 1-12.

Mason, L. \& Scrivani, L. (2004). Enhancing students' mathematical beliefs: An intervention study. Learning and Instruction, 14, 153-176.

McLeod, D. B. (1989). Beliefs, attitudes, and emotions: New views of affect in mathematics education, In D. B. McLeod \& V. M. Adams (Ed.), Affect and mathematical problem solving: A new perspective (pp. 245-258). New York: Springer-Verlag.

McLeod, D. B (1992). Research on affect in mathematics education: A reconceptualization. In D.A Grouws (Ed.), Handbook of research on mathematics teaching and learning (pp.575 -596). New York: Macmillan.

McLeod, D. B. \& McLeod, S. H. (2002). Synthesis-beliefs and mathematics education: Implications for learning, teaching and research. In G. C. Leder, E. Pehkonen \& G. Törner (Ed.), Beliefs: A hidden variable in mathematics education? (pp. 115-127). Dordrecht: Kluwer Academic Publishers.

Moscucci, M. (2007). About mathematical belief system awareness. Paper presented at the Europen Research in Mathematics Education V, Larnaca, Cyprus, 22-26 February.

Op't Eynde, P. \& De Corte, E. (2004). Junior high school students' mathematics-related belief systems: Their internal structure and external relations. Paper presented in the Topic Study Group at the10th International Congress on Mathematical Education, Copenhagen, Denmark.

Paksu, A. D. (2008). Comparing teachers' beliefs about mathematics in terms of their branches and genders. Hacettepe University Journal of Education, 35, 87-97.

Pehkonen, E. \& Pietila, A. (2003). On relationships between beliefs and knowledge in mathematics education. Europian Research in Mathematics Education 3, 1-8.

Pehkonen, E. \& Törner, G. (1996). Mathematical beliefs and different aspects of their meaning. International Reviews on Mathematical Education (ZDM), 28(4), 101-108.

Pajares, M. F. (1992). Teachers' beliefs and educational research: Cleaning up a messy construct. Review of Educational Research, 62(3), 307-332.

Perkins, K. K., Adams, W. K., Pollock, S. J., Finkelstein, N. D. \& Wieman, C. E. (2004). Correlating students' beliefs with student learning using the coloradoe learning attitudes about science survey. Paper presented at the Physic Education Research Conference, California, USA, 4-5 August. 
Raymond, A. M. (1997). Inconsistency between a beginning elementary school teacher's mathematics beliefs and teaching practice. Journal for Research in Mathematics Education, 28(5), 550-576.

Rokeach, M. (1968). Beliefs, attitudes, and values: A theory of organization and change. San Francisco: Jossey-Bass.

Schoenfeld, A. H. (1989). Explorations of students' mathematical beliefs and behavior. Journal for Research in Mathematics Education, 20(1), 338-355.

Schommer-Aikins, M., Duell, O. K. \& Hutter, R. (2005). Epistemological beliefs, mathematical problemsolving, and academic performance of middle school students. The Elementary School Journal, 105(3), 289-304.

Southwell, B. \& Khamis, M. (1994). Beliefs about mathematics and mathematics education. Paper presented at the MERGA Conference, Brisbane, Australia.

Spangler, D. (1992). Assessing students' beliefs about mathematics. The Mathematics Educator. 3(1), 1925.

Star, J. R.,\& Hoffmann, A. J. (2005). Assessing the impact of standards-based curricula: Investigating students' epistemological conceptions of mathematics. The Mathematis Educator, 15(2), 25-34.

Suthar, V. \& Tarmizi, R. A. (2010). Effects of students' beliefs on mathematics and achievement of university students: Regression analysis approach. Journal of Social Sciences, 6(2), 146-152.

Tarmizi, R. A. \& Tarmizi, M. A. A. (2010). Analysis of mathematical beliefs of Malaysian secondary school students. Procedia Social and Behavioral Sciences, 2, 4702-4706.

Törner, G. (2001). Mentale Repräsentationen - der Zusammenhang zwischen 'Subject-Matter Knowledge' und 'Pedagogical Content Knowledge' - dargestellt am Beispiel der Exponentialfunktionen in einer Fallstudie mit Lehramtsstudenten. In G. Kaiser (Ed.), Beiträge zum Mathematikunterricht (pp. 628631). Hildesheim: Franzbecker.

Uçar, Z. T., Pişkin, M., Akkaş, E.N. ve Taşçı, D. (2010). İlköğretim öğrencilerinin matematik, matematik öğretmenleri ve matematikçiler hakkındaki inançları. Eğitim ve Bilim, 35(155), 131-144.

Umay, A. (2007). Eski arkadaşımız okul matematiğinin yeni yüzü. Ankara: Aydan Web Tesisleri.

Vanayan, M., White, N., Yuen, P. \& Teper, M. (1997). Beliefs and attitudes toward mathematics among third and fifth grade students: A descriptive study. School Science and Mathematics, 97(7), 345-351.

White, A. L., Way, J., Perry, B. \& Southwell, B. (2005-2006). Mathematical attitudes, beliefs and achievement in primary pre-service mathematics teacher education. Mathematics Teacher Education and Development, 7, 33-52.

Wilkins, J. L. M. \& Ma, X. (2003). Modeling change in student attitude toward and beliefs about mathematics. The Journal of Educational Research, 97(1), 52-63.

Yıldıım, A. ve Şimşek, H. (2011). Sosyal bilimlerde nitel araştırma yöntemleri. Ankara: Seçkin Yayıncılık. 


\section{Extended Abstract}

\section{Introduction}

Students' beliefs about mathematics have an important place in mathematics education (McLeod, 1989; Moscucci, 2007). Mathematical trend of the students is associated with their beliefs about mathematics (Wilkins \& Ma, 2003). These beliefs greatly influence students' approach to mathematics and mathematical tasks (Garofalo, 1989). Cobb (1986) defines belief as the personal assumptions about the nature of the reality; while Schoenfeld (1989) define mathematical belief as the approach of the individual toward mathematics and mathematical tasks. According to Raymond (1997) mathematical belief is the personal judgments of the individuals, shaped as a result of their mathematical experiences.

Students' mathematical beliefs have significant effects on their mathematic success and mathematical skills (Kloosterman \& Cougan, 1994; Mason \& Scrivani, 2004; Schommer-Aikins, Duell, Hutter, 2005; Suthar \& Tarmizi, 2010), as well as their mathematical behaviors and decisions (Goldin, Rösken \& Törner, 2009; Kloosterman \& Cougan, 1994; Pajares, 1992). Students who are highly successful in mathematics have more positive beliefs about it compared to other students. At the same time, mathematics achievement of the students who love mathematics is also quite high. Students' beliefs also affect their learning goals (Cobb, 1986). It is a known fact that learning goals have a significant impact on learning. This case shows that the beliefs that students possess, have a direct or indirect impact on their learning.

\section{Purpose}

Students' beliefs about mathematics are very strongly associated with their learning process (Opt'y Eynde \& De Corte; 2004). Teachers have a major impact on the formation of the students' beliefs about mathematics during the learning process (Lazim, Abu Osman, Salihin, 2004). This strong impact of the teachers on students' mathematical beliefs reveals the importance of the teacher's role in the classroom. Being aware of students' mathematical beliefs is important in terms of preparing appropriate learning environments and the assessment of learning process (Kislenko, Grevholm \& Lepik, 2005; Spangler, 1992). Within this scope, new studies that will reveal students' mathematical beliefs are needed. In this context, the purpose of this study is to determine the beliefs of middle school students about mathematics.

\section{Method}

This research has been carried out using a qualitative approach. In this study, phenomenological design was used to determine students' beliefs about mathematics. The main objective of phenomenological research is to reveal the meanings that individuals created towards a phenomenon as the results of the experiences that they have encountered (Creswell, 2007). In this research, students' beliefs about mathematics were determined via the metaphors created by them.

\section{Results and Discussion}

A total of 252 middle school students $\left(6^{\text {th }}, 7^{\text {th }}\right.$ and $8^{\text {th }}$ grades $)$ participated in this research. Three open-ended questions were asked to the students to reveal their mathematical beliefs: (i) If you have to liken mathematics to a color, which color would you choose, why? (ii) If you have to liken mathematics to an object, which object would you choose, why? (iii) If you have to liken mathematics to an animal, which animal would you choose, why? Students were asked to answer these questions in writing. Mathematical beliefs of the students were be determined regarding the metaphors that used to answer these questions and 
the reasons of choosing these metaphors were also examined. The data were analyzed using content analysis. Data obtained from each question were analyzed separately. During the data analysis process, the answers given to open-ended questions were analyzed first and coding was performed separately for each question. Following the preliminary coding, common codes were formed and another coding was performed. After the completion of coding, different themes were created for each question and inferences were driven. To support these themes and inferences, direct quotations from the explanations of the students were taken. Moreover, the frequency and percentage of students were calculated for each theme.

Based on the findings of the research, it has was that the majority of the students (33.9\%) see mathematics as informative. In addition, students stated that mathematics is necessary and useful, it facilitates life. Another important finding is that $24.8 \%$ of the student defined mathematics as numbers and operations. Students stated that memorization and repetition are important for mathematics. Students' beliefs about mathematics as being formed only by numbers and operations that memorization is important are among the most common findings of previous studies (Kayaaslan, 2006; Schoenfold, 1989; Southwell \& Khamis, 1994; Spangler, 1992; Vanayan, White, Yuen \& Teper, 1997). Another interesting finding was that $27.7 \%$ of the students expressed that mathematics requires mind and intelligence. Students stated that intelligent people may be successful in math. About seven percent of the students defined mathematics as a communication device.

It was found that beliefs of $69 \%$ of the students are positive, $23 \%$ of the students have is negative beliefs and $8 \%$ of them have both positive and negative beliefs. It is difficult to say that a small number of students have negative beliefs about mathematics whereas the majority of the students have positive beliefs. It was seen that these students have very sharp beliefs (difficult, nightmare, sadness, boring, pessimistic). These beliefs of the students also have a significant impact, shaping their approach to mathematics and mathematical tasks (Garofalo, 1989), as well as determining their interaction with the learning environment in the classroom (Opt'y Eynde \& De Corte, 2004). This fact reveals that changing students' negative beliefs and enhancing positive beliefs is a necessity for the formation of an effective learning process. In this regard the role of the teachers is crucial. 